\title{
The future of Digital Student Data Portability: the Groningen Declaration
}

\author{
Giralt, $\mathrm{V}^{1}$, De Leeuw, $\mathrm{H}^{2}$ \\ ${ }^{1}$ Central ICT Services, University of Málaga, Málaga, Spain, victoriano@uma.es \\ ${ }^{2}$ Dienst Uitvoering Onderwijs (DUO), Groningen, Netherlands, herman.deleeuw@duo.nl \\ Keywords \\ Groningen Declaration, Student Data portability, Digital Student Depositories, RS3G.
}

\section{ABSTRACT}

Paper based diplomas are easy to forge and require a noticeable amount of expertise to verify, especially when presented in a different country from the one that produced them. The so-called diploma mills, illegal operations that sell fake degrees, are running rampant at the moment. Moving to fully digital diplomas can prevent these problems. Digital identity technologies can be used for providing controlled access to verifiable information about an individual academic achievement.

The Groningen Declaration has become the centre of a world wide effort to join efforts dedicated to the creation of Digital Diploma Deposits, encompassing developments from China through Mexico and Norway through South Africa. At the core of this efforts lays the work of groups like EUNIS's own RS3G (Rome Students Systems and Standards Group), EAIE's DSDP (Digital Student Data Portability), USA National Student Clearing House or TERENA TF-EMC2.

The aim of the present paper and the corresponding presentation is to increase awareness in the European University ICT community of the efforts that surround the Declaration, by presenting the achievements of the first year of its existence, like the meeting that took place in April 2013 in Beijing hosted by CHESSIC and the Chinese MoE.

\section{THE GRONINGEN DECLARATION}

The Groningen Declaration was first presented to the world in April 2012 as the main activity of the first Digital Student Data Depositories Worldwide seminar at the University of Groningen, and EUNIS was among the first group of signers.

This is the opening paragraph of the Groningen Declaration on Digital Student Data Depositories World Wide:

"We, the signatories of this Groningen Declaration on Digital Student Data Depositories Worldwide, are witnessing a growing awareness in large parts of the worlds of politics and academics, as well as in public opinion, of the need to establish a more complete and far-reaching delivery of digital student data. As we see it, digital student data portability and digital student data depositories are becoming increasingly concrete and relevant realities, and in the years to come, they will contribute decisively to the free movement of students and skilled workers on a global scale."

And these are a sample of the points to which the signatories pledge:

"We consider the following issues - ownership of data sets; privacy rights, identification; access; consulting; forwarding/sharing; compatibility; comparability; acceptance; and recognition - in order to establish a global area of convergence on digital student data depositories, and we pledge to share best practices in digital secure systems and to co-ordinate our policies on:

- the purpose, feasibility and cost-efficiency of worldwide exchange of digital student data

- the ways to make our systems more compatible, inter alia by looking into semantic interoperability

- the ways to make data more easily comparable

- promoting acceptance, for purposes of recognition, of digital student data in lieu of paper documents 
- adherence to national or federal privacy rights, both at the sending and at the receiving ends, when data are transferred

- phasing out of paper based documents and of paper based authentications (legalisations) where practicable".

\section{PRESENT}

During the first year of existence, the group of professionals and organisations that gather around and promote the Groningen Declaration has managed to increase the number of signatories to 17 from the five continents and organise the second Digital Student Data Depositories Worldwide seminar in Beijing in April 2013, hosted by CHESSIC, with almost a hundred attendees. The seminar has allowed for the establishment of several collaboration accords that will result in pilots for data student exchange that will materialise during the coming year. This has been supported by the presentation of already in production or almost ready digital depositories in many countries.

There are no established data interchange standards for student data, neither for achievements nor diplomas or certificates. The current pilots will mostly use PDF with mechanism for online verification.

The combination of all the paperwork needed for international studies, the difficulties in the recognition and verification of paper certificates and the rampant forgeries of such paper documents are an important hindrance to both student and professional mobility in Europe and worldwide. Moving this information into the digital realm as proposed in the Groningen Declaration would result in an immediate fall of many barriers.

The group has opened the recruitment office to assemble as much help as possible to achieve the goals described in the Declaration.

\section{FUTURE}

The short term goals for the support group of the declaration are the exchange pilots between countries, increase awareness of the need of national depositories and create a task force dedicated to the creation of technical documents. Medium term goals are influencing or helping the creation of standards for electronic student data exchange and laws that favour the use of digital documents over paper based ones.

On the promotional side, it has already been decided that the third DSDDW seminar will be held in Washington, D.C. in 2014.

A side effect of achieving ubiquitous Digital Student Portable Data will be the possibility of an Erasmus Without Papers, thus improving the experience of moving European students.

\section{REFERENCES}

Groningen Declaration website (2013). The Groningen Declaration. Retrieved May 5, 2013, from: http://www.groningendeclaration.org/.

DSDDW 2013 website (2013). CHESSIC - Digital Student Data Depositories Worldwide 2013. Retrieved May 5, 2013, from: https://account.chsi.com.cn/z/dsddw/meeting.jsp.

\section{AUTHORS' BIOGRAPHIES}

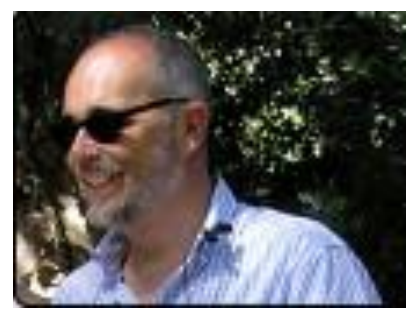

V. Giralt is the systems manager for the University of Málaga. Graduated as an MD from University of Málaga in 1986, and became a member of the University IT team in 1987 as a programmer. Has worked as a programmer for the University and systems administrator both for the International University of Andalusia (1990-1995) and the University of Málaga. Chairs the technical committee of the Confia Identity Federation for the Andalusian public universities and the Groningen Declaration Executive Committee. Member of the steering committee of RS3G EUNIS task force, 
member of the European Committee for Academic Middleware, member of the TERENA EMC2 task force, acting as co-chair during 2012, member of the RedIRIS identity task force, member of the SSEDIC EU expert network on electronic identity.

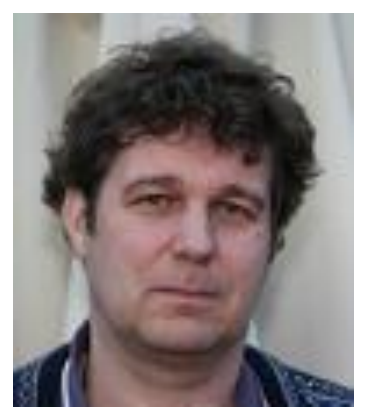

H. de Leeuw studied Arabic language and literature at Leiden University, the Netherlands, graduating in 1988. From 1985 to 1991, he worked as a cataloguer/bibliographer in the antiquarian book trade, specializing in antiquarian Oriental books and manuscripts. This may have prepared him for entering the esoteric field that he got involved in since: Credential evaluation and recognition, including the burning issue of authenticity. Starting in the field with Nuffic, in 1991, he moved in 2001 to the Dienst Uitvoering Onderwijs (Education Executive Agency), an agency directly under the Netherlands Ministry of Education, based in Groningen, the Netherlands where he is still based. In 2006, Herman was trained as forensic document researcher at the Netherlands Police Academy. Herman is active in EAIE's ACE Board (Admissions Officers Credential Evaluators) from 2006 onwards, first as a board member (2006-2008), from 2008 till 2012 as the chair, and for 2012-2014 as a member of the General Council for ACE. Herman has been bringing authenticity and forgery issues to the fore within EAIE, in the form of conference sessions and workshops, training courses during the year, and by a number of articles on authenticity issues and forgeries. Herman is the current secretary of the Groningen Declaration Executive Committee. 